\title{
Reconstructive methods to resolve intractable fistulas that develop after radiation therapy in patients with head and neck cancer
}

Bu Hyeon Choi, Seong Oh Park, Hee Chang Ahn

Department of Plastic and Reconstructive Surgery, Hanyang University College of Medicine, Seoul, Korea
Background: Radiation therapy (RT) is frequently used for supportive treatment and management of advanced head and neck cancers. This study performed a retrospective review of the treatment methods that were used for intractable draining fistulas in seven patients who had received RT for head and neck cancers. Treatment methods used for two of the seven patients are presented in detail.

Methods: From 2009 to 2020, seven patients underwent reconstructive surgery for intractable fistulas which occurred after RT for head and neck cancers. Patient characteristics, medical history, treatment method, and treatment outcome were reviewed for each case. The type of surgery performed, failure rate, and treatment period were also analyzed.

Results: In this study, a total of seven patients received additional management for radiation-induced fistulas. Patients underwent a mean of $3.3 \pm 1.4$ surgeries (maximum: six surgeries) to resolve their fistulas. The mean time interval from the first surgery to the last surgery for the patients to achieve resolution of the fistula was 8.7 months. Loco-regional flaps have performed an average of $1.9 \pm 1.5$ times. However, all loco-regional flaps failed. Instead, the patients' intractable fistulas were resolved with the use of distant flaps or free tissue transfers.

Conclusion: Fistulas that develop after head and neck cancer treatment following RT are difficult to treat with simple loco-regional flap procedures. Therefore, more aggressive treatment techniques, such as distant flap or free tissue transfer, may be needed to shorten patients' treatment periods and avoid unnecessary surgeries.

Abbreviations: ALT, anterolateral thigh; FOCF, fibular osteocutaneous free flap; HNC, head and neck cancer; LDMC, latissimus dorsi myocutaneous; PMMC, pectoralis major musculocutaneous; RAMC, rectus abdominis musculocutaneous free flap; RFFF, radial forearm free flap; RT, radiation therapy.

Keywords: Fistula / Free tissue flaps / Head and neck neoplasms / Radiotherapy

\section{INTRODUCTION}

Radiation therapy (RT) is an effective treatment method for

\section{Correspondence: Hee Chang Ahn}

Department of Plastic and Reconstructive Surgery, Hanyang university College of

Medicine, 222-1 Wangsimni-ro, Seongdong-gu, Seoul 04763, Korea

E-mail: ahnhc@hanyang.ac.kr

Received August 9, 2021 / Revised August 25, 2021 / Accepted October 20, 2021 head and neck cancer (HNC) and is a principal curative modality [1]. Most patients with HNC (80\%; range, $73.9 \%-84.4 \%)$ receive RT [2]. Although RT is indispensable for HNC treatment, patients who are treated with RT experience acute or chronic side effects that include oral health deterioration, orocutaneous fistula formation, and osteoradionecrosis [3].

Orocutaneous fistula formation is a serious complication of 
RT that leads to wound infection, dysphasia, dysphagia, rupture of anastomotic vessels, and carotid blowout syndrome, which is defined as the rupture of the extracranial carotid artery or its branches, resulting in high morbidity and mortality [4-6]. Moreover, complications caused by a fistula can reduce a patient's quality of life and make timely postoperative chemotherapy and radiotherapy administration difficult $[7,8]$.

Wound healing in a previously irradiated neck region is often impaired by widespread scarring, fibrous tissue remodeling, and altered perfusion of irradiated tissues $[9,10]$. Consequently, fistula resolution in the irradiated neck region is difficult to achieve.

Improvement in patient outcome for the treatment of $\mathrm{HNC}$ complications depends on the selection of an appropriate surgical approach. In this study, we retrospectively reviewed our approaches for treating intractable fistulas that developed in seven patients after RT. We also discussed in detail the treatment methods used in two representative cases.

\section{METHODS}

From 2009 to 2020, 62 cases received free tissue transfers for $\mathrm{HNC}$ reconstruction and 58 patients underwent surgery. A retrospective review of medical records was conducted to identify patients with fistulectomies and reconstructive surgeries for intractable fistulas. Patients who underwent RT were included. Patients were excluded from the study if they had undergone surgery for $\mathrm{HNC}$ and did not receive $\mathrm{RT}$, or if their medical and clinical records were insufficient. A follow-up history of at least 1 year was a requirement for inclusion in the study.

The following data were analyzed with a retrospective observational study design: the number of surgeries, number of locoregional surgeries, number of distant flap and free flap performed, number of additional surgeries needed after distant flap or free flap treatment, duration (months) from the first surgery to the last surgery, and type of surgery that led to fistula resolution.

This study was approved by the hospital's institutional review board (IRB No. 2021-06-026) and was conducted in accordance with the principles of the Declaration of Helsinki. All participants provided written informed consent.

\section{Conservative management}

When fistulas developed, conservative management was initially attempted in all cases. Oral feeding was replaced with nasogastric tube feeding or parenteral nutrition with fasting. Empirical antibiotic and anti-inflammatory drug treatments were initiated. We performed bacterial cultures of the wounds and changed the antibiotics based on the antibiotic susceptibility test results for bacterial pathogens. Daily local wound management, including debridement of necrotic tissue and curettage of the fistulous borders, was undertaken. If a patient's symptoms did not improve after 3 weeks of conservative management, additional surgical management was considered [11].

\section{Surgical principle}

When conservative methods failed, surgical closure of a fistula was indicated. The surgical method used was based on the size of the fistula and the condition of the surrounding soft tissues. For fistulas $<2 \mathrm{~cm}$ in diameter and with mild inflammation of the surrounding tissues, loco-regional flaps were initially attempted. For fistulas with diameters $\geq 2 \mathrm{~cm}$, multiple fistulas, or fistulas with severe inflammation of the surrounding tissues, a free tissue transfer with good vascularity was the primary treatment choice. If the recipient vessels or donor site vessels were not patent due to previous surgery or RT, a distant flap, such as a pectoralis major musculocutaneous (PMMC) flap or a pedicled latissimus dorsi myocutaneous (LDMC) flap, was used as a second choice for surgical treatment.

Fistula closures involved two epithelial surfaces; one provided an internal lining and the second provided external coverage [12]. In cases involving oral or esophageal mucosal reconstruction, the mucosal lining and the skin layer were simultaneously reconstructed using two skin paddles to preserve the original anatomy as much as possible. If two skin paddles were insufficient for covering the defect, two flaps were harvested to cover the internal mucosa and skin lining, respectively. In addition, the muscle layer of the donor site was harvested to create a layer that was resistant to fistula formation, and secured flap vascularity. During closure of the mucosal layer, a watertight vertical mattress suture was applied to ensure sealing, thereby preventing a recurrence of the fistula.

\section{RESULTS}

Seven patients (five males and two females) who were treated for fistulas from 2009 to 2020 were included in the study. Three patients had orocutaneous fistulas, two patients had oronasal fistulas, one patient had an esophagocutaneous fistula, and one patient had an oroantral fistula. One patient received preoperative RT, while six patients were treated with RT postoperatively. Three patients underwent chemotherapy with RT (Table 1).

Five loco-regional flaps, one distant flap, and one free flap were initially attempted for fistula repair; however, these procedures were unsuccessful. Six free flaps and one pedicled LDMC flap were the last surgeries performed in the patients. The last 
Table 1. Characteristics of patients

\begin{tabular}{|c|c|c|c|c|c|c|c|c|c|c|}
\hline \multirow{2}{*}{$\begin{array}{l}\text { Patient } \\
\text { No. }\end{array}$} & \multirow{2}{*}{$\begin{array}{c}\text { Sex/age } \\
\text { (yr) }\end{array}$} & \multirow[b]{2}{*}{ Type of cancer } & \multirow{2}{*}{$\begin{array}{l}\text { Last salvage } \\
\text { reconstruction }\end{array}$} & \multirow{2}{*}{$\begin{array}{l}\text { Radiation } \\
\text { therapy }\end{array}$} & \multirow{2}{*}{$\begin{array}{l}\text { Chemo- } \\
\text { therapy }\end{array}$} & \multirow[b]{2}{*}{ Fistula type } & \multirow[b]{2}{*}{ Fistula location } & \multirow{2}{*}{$\begin{array}{l}\text { Initial } \\
\text { attempt flap }\end{array}$} & \multicolumn{2}{|c|}{ Before the last surgery } \\
\hline & & & & & & & & & $\begin{array}{l}\text { Loco-regional } \\
\text { flap }\end{array}$ & $\begin{array}{l}\text { Distant or free } \\
\text { flap }\end{array}$ \\
\hline 1 & $F / 26$ & Tongue cancer & RFFF+RAMC & Postoperative & No & Orocutaneous & Chin & Local & 1 & - \\
\hline 2 & $M / 16$ & Buccal cancer & $\mathrm{FOCF}+\mathrm{ALT}$ & Postoperative & No & Orocutaneous & Chin & Free & 1 & 1 (FOCF) \\
\hline 3 & $M / 68$ & Parotid gland cancer & RFFF & Postoperative & No & Orocutaneous & Chin & Local & 1 & - \\
\hline 4 & $\mathrm{M} / 40$ & Palate cancer & FOCF & Postoperative & No & Oronasal & Hard palate & Local & 2 & - \\
\hline 5 & $M / 48$ & Palate cancer & RFFF & Postoperative & Yes & Oronasal & Hard palate & Local & 5 & - \\
\hline 6 & $\mathrm{M} / 70$ & Tongue cancer & LDMC & Preoperative & Yes & Esophagocutaneous & Neck & Distant & 1 & 1 (PMMC) \\
\hline 7 & $F / 38$ & Buccal cancer & ALT & Postoperative & Yes & Oroantral & Buccal mucosa & Local & 2 & 1 (ALT) \\
\hline
\end{tabular}

M, male; F, female; RFFF, radial forearm free flap; RAMC, rectus abdominis musculocutaneous free flap; FoCF, fibular osteocutaneous free flap; ALT, anterolateral thigh; LDMC, latissimus dorsi myocutaneous flap; PMMC, pectoralis major musculocutaneous.

salvage reconstructions included two radial forearm free flaps, one fibular osteocutaneous free flap, and one anterolateral thigh free flap. Two patients received double free flaps that included: radial forearm flap and rectus abdominis flap, and fibular bone flap and anterolateral thigh flap (Table 1).

An average of $3.3 \pm 1.4$ surgeries was required to resolve the fistulas and an average of $1.9 \pm 1.5$ loco-regional surgeries and $1.4 \pm 0.5$ distant flaps or free flaps were performed. Only three patients required additional surgery after distant flap or free flap. The mean time interval from the first surgery to the last surgery was $8.7 \pm 15.0$ months. The failure rate of the loco-regional flap method was $100 \%$; the combined distant flap and free flap failure rate was 30\% (Table 2).

\section{DISCUSSION}

Despite clinical and medical advancements, the incidence of $\mathrm{HNC}$ is increasing and places a burden on public health due to the serious morbidity and mortality rates [13]. Recently, immediate elective repair using free tissue transfer has become an important treatment modality for reconstruction after HNC surgeries. Additionally, secondary free tissue transfer is used as a salvage method for the treatment of cancer recurrence, primary flap failure, or RT-related complications [14].

Distant flaps, such as the pectoralis major flap, deltoid flap, or latissimus dorsi flap, are still commonly used in reconstruction following HNC surgeries along with free tissue transfer. Distant flaps are also considered valid reconstruction tools when the primary free flap fails, or salvage reconstruction is needed due to other complications [15].

In contrast, loco-regional flaps can be used for small- to medium-sized defects of the head and neck; however, they are unsatisfactory for use in an irradiated field. RT elicits a series of inflammatory responses that lead to a radiation-induced fibroatrophic effect [16]. If the radiation-induced fibroatrophic ef-
Table 2. Characteristics of reconstruction surgery

\begin{tabular}{|c|c|c|c|}
\hline Characteristics & Value & Min & Max \\
\hline No. of surgeries & $3.3 \pm 1.4$ & 2 & 6 \\
\hline No. of loco-regional surgeries & $1.9 \pm 1.5$ & 1 & 5 \\
\hline No. of distant flaps or free flaps & $1.4 \pm 0.5$ & 1 & 2 \\
\hline $\begin{array}{l}\text { Additional surgeries needed after distant flap or } \\
\text { free flap }(n=7)\end{array}$ & 3 & & \\
\hline Duration from first surgery to last surgery (mo) & $8.7 \pm 15.0$ & $14^{\mathrm{a})}$ & 42 \\
\hline Loco-regional surgery failure rate (\%) & 100 & & \\
\hline Distant flap or free flap failure rate (\%) & 30 & & \\
\hline
\end{tabular}

Values are presented as the mean \pm SD or number.

a)Days.

fect occurs in a soft tissue around the neck, delayed wound healing can lead to fistula formation even when a free tissue transfer with good vascularity was used for reconstruction. These fistulas fail to heal with loco-regional flaps due to surrounding soft tissue fibrosis and impaired vascularity. In our study, all loco-regional flap surgeries failed. The combined failure rate of distant flap and free flap surgeries was 30\%, and at least one distant flap or free flap was required to resolve the draining fistula.

Recipient vessel selection is limited in previously irradiated neck region. In these cases, the use of distant flaps such as PMMC flaps may be a suitable option for reconstructive surgery [17]. These flaps use multiple skin paddles and harvest muscle layers to reduce damage to the perforators, secure vascularity, and provide barriers to the fistulas. The use of distant flaps can shorten patients' clinical courses and avoid unnecessary surgeries. The patient described in the first case lacked suitable recipient vessels in the neck for a successful free flap procedure (Fig. 1). Therefore, the reconstruction was performed with a pedicled LDMC flap that provided good vascularity. Although the patient's fistula recurred once after the procedure, it was successfully treated with conservative measures.

Successful free tissue transfers are significant since they affect 

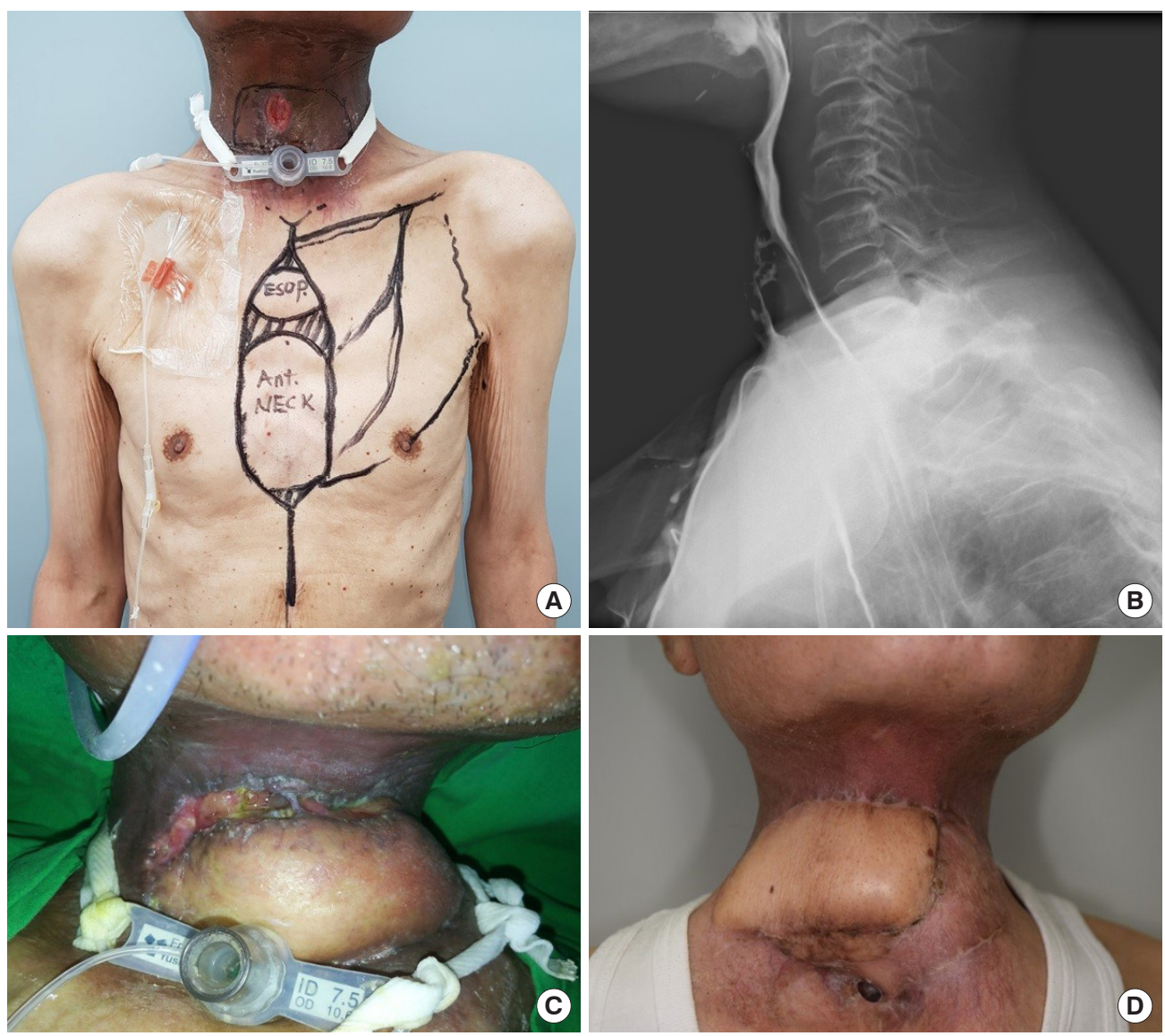

Fig. 1. Case 1 (patient no. 6.) A 70-year-old man presented with recurrent tongue cancer that had been treated with chemoradiotherapy. Tumor resection, total laryngectomy, total glossectomy, bilateral modified radical neck dissection, and reconstruction with an anterolateral thigh free flap were performed. (A) An esophagocutaneous fistula developed 1 month after glossal reconstruction; salvage reconstruction using a pectoralis major musculocutaneous flap was planned due to vessel-depleted neck. (B) An esophagogram showed the presence of an esophagocutaneous fistula and tracheal aspiration. (C) The esophagocutaneous fistula recurred after the pectoralis major musculocutaneous flap had been performed. (D) Resolution of the fistula and healing were observed 8 months after treatment with a pedicled latissimus dorsi myocutaneous flap.

patients' morbidity and mortality. Many factors are vital to the success of microscopic surgery; however, selecting an appropriate recipient vessel is one of the most significant factors [18]. In particular, patients with vessel-depleted neck who had undergone RT or a previous surgery lack suitable recipient vessels for free flap. At our institution, after checking the available recipient vessels using neck computed tomography angiography, the recipient vessels were selected outside the radiation field. The location of the soft tissue defect is the primary factor in the selection of recipient vessels. For upper head defects, the superficial temporal artery and vein or the middle temporal vein are the vessels of choice due to adequate caliber and ease of localization $[19,20]$. For lower head and neck defects, the superior thyroid artery and the external jugular vein are preferred, but these have often already been used for previous reconstructive surgery $[21,22]$. The facial or transverse cervical blood vessels can alternatively be used as another option for recipient vessels
$[18,23]$. However, if these vessels are unavailable due to previous surgery or irradiation, the contralateral recipient vessels or distant flap should be considered [24]. In the second case presented in this study, the superficial temporal artery and middle temporal vein were used in the patient to resolve the oroantral fistula and the contralateral side vessels were used to resolve the orocutaneous fistula (Fig. 2). If all the methods are unfeasible, then the pectoral branch of the thoracoacromial artery or the internal mammary vessels can be used [25].

Due to the high loco-regional surgical failure rate, a distant flap or free flap with good vascularity is required for wound healing to occur. In addition, since the time interval between the first and last surgery is prolonged in these patients, unnecessary loco-regional surgery should be avoided. Therefore, if no improvement occurs after a sufficient period of conservative treatment, a distant flap or free tissue transfer should be considered for shortening the treatment periods and to reduce unnec- 

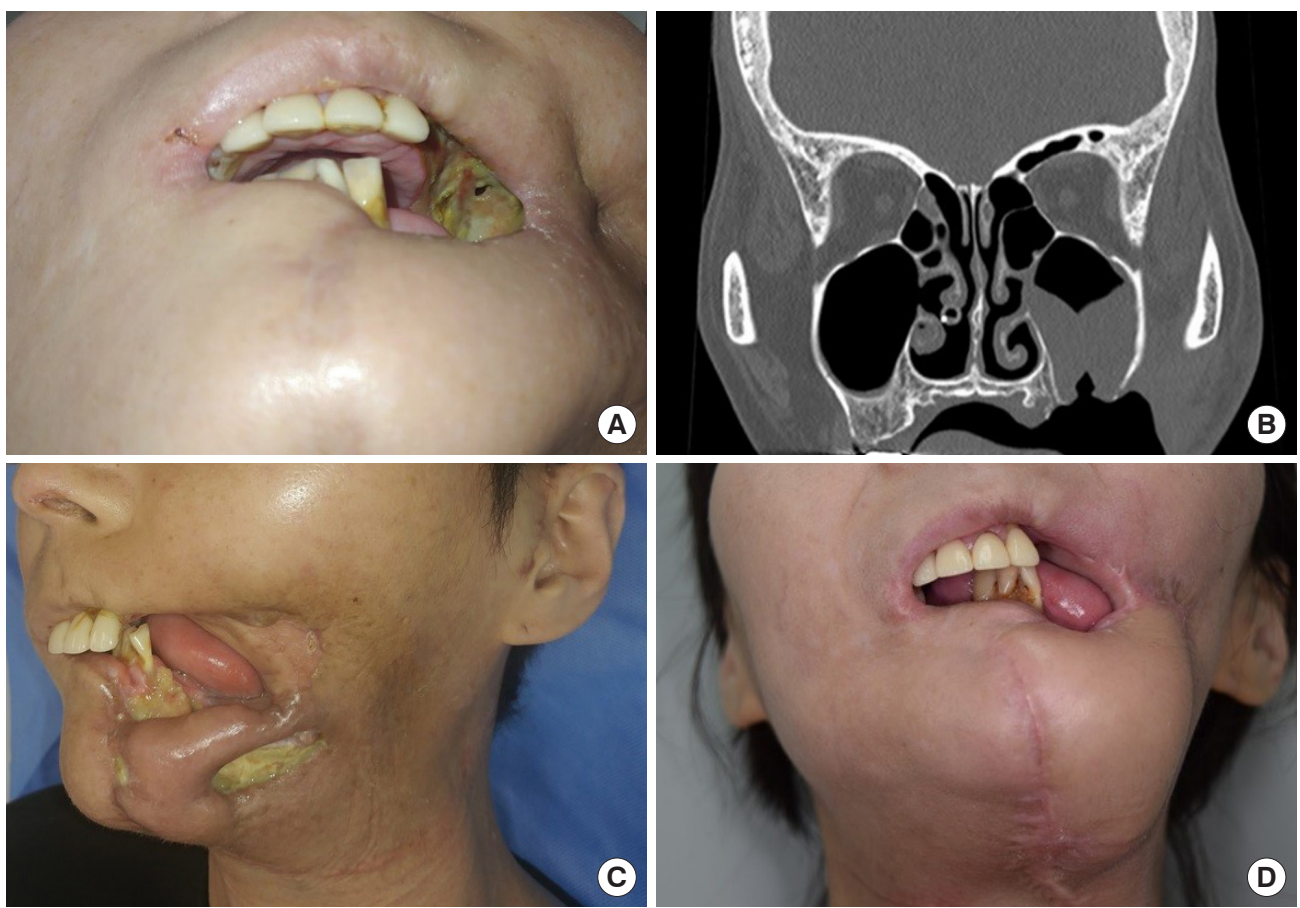

Fig. 2. Case 2 (patient no. 7.) A 38-year-old woman with systemic lupus erythematosus and antiphospholipid syndrome presented with recurrent buccal cancer after previous treatment with tumor resection and left neck dissection. The patient underwent tumor resection and segmental mandibulectomy. Due to poor vessel patency in the left neck, the patient was administered a reconstructive pectoralis major musculocutaneous flap and adjuvant chemoradiation. (A) An oroantral fistula developed on postoperative day 46. (B) Facial computed tomography demonstrated the oroantral fistula and maxillary sinusitis. (C) The oroantral fistula was treated with an anterolateral thigh free flap using the superficial temporal artery and middle temporal vein as recipient vessels. However, an orocutaneous fistula developed in the left mandibular and mid chin areas. (D) The orocutaneous fistula was completely resolved following an anterolateral thigh free flap performed with the superficial thyroid artery and external jugular vein as recipient vessels.

essary surgeries for HNC patients who have undergone RT [26].

This study had several limitations. First, a selection bias may have occurred because of the retrospective study design. Second, there was an insufficient number of patients for a control group. Finally, statistical analyses could not be performed due to the small number of cases. Despite these limitations, we analyzed the appropriateness of the surgical treatments for the patients. Therefore, this study makes a valuable contribution for the small number of patients that require reconstructive surgery for intractable fistulas following RT for HNC.

Based on the study results, we suggest an approach to shorten patients' treatment periods and reduce unnecessary surgeries for the treatment of fistulas that require reconstruction after RT for HNC. Free tissue transfers or distant flaps are often more invasive than loco-regional flaps and are difficult to perform [27]. However, when no improvement is achieved after a sufficient period of time with conservative management, free tissue transfers or distant flaps should be considered to shorten the treatment period.

\section{NOTES}

\section{Conflict of interest}

No potential conflict of interest relevant to this article was reported.

\section{Ethical approval}

The study was approved by the Institutional Review Board of Hanyang University Seoul Hospital (IRB No. 2021-06-026) and performed in accordance with the principles of the Declaration of Helsinki. Written informed consent was obtained.

\section{Patient consent}

The patients provided written informed consent for the publication and the use of their images.

\section{ORCID}

Bu Hyeon Choi https://orcid.org/0000-0003-4171-1303 Seong Oh Park https://orcid.org/0000-0001-8990-0635 Hee Chang Ahn 


\section{Author contribution}

Conceptualization: Seong Oh Park, Hee Chang Ahn. Data curation: Bu Hyeon Choi. Formal analysis: Seong Oh Park. Methodology: Seong Oh Park. Writing - original draft: Bu Hyeon Choi. Writing - review \& editing: Bu Hyeon Choi, Seong Oh Park, Hee Chang Ahn. Investigation: Bu Hyeon Choi. Supervision: Hee Chang Ahn.

\section{REFERENCES}

1. Bhide SA, Newbold KL, Harrington KJ, Nutting CM. Clinical evaluation of intensity-modulated radiotherapy for head and neck cancers. Br J Radiol 2012;85:487-94.

2. Borras JM, Barton M, Grau C, Corral J, Verhoeven R, Lemmens $\mathrm{V}$, et al. The impact of cancer incidence and stage on optimal utilization of radiotherapy: methodology of a population based analysis by the ESTRO-HERO project. Radiother Oncol 2015;116:45-50.

3. Sroussi HY, Epstein JB, Bensadoun RJ, Saunders DP, Lalla RV, Migliorati CA, et al. Common oral complications of head and neck cancer radiation therapy: mucositis, infections, saliva change, fibrosis, sensory dysfunctions, dental caries, periodontal disease, and osteoradionecrosis. Cancer Med 2017;6:291831.

4. Shin JY, Lee SY, Roh SG, Lee NH. Effects of perioperative radiation treatment on stricture and fistula formation in hypopharyngeal reconstruction: a meta-analysis. Arch Craniofac Surg 2021;22:71-7.

5. Jeong WS, Oh TS. Oral and oropharyngeal reconstruction with a free flap. Arch Craniofac Surg 2016;17:45-50.

6. Suarez C, Fernandez-Alvarez V, Hamoir M, Mendenhall WM, Strojan P, Quer M, et al. Carotid blowout syndrome: modern trends in management. Cancer Manag Res 2018;10:5617-28.

7. Al Deek NF, Wei FC, Tsao CK. Fistulae after successful free tissue transfer to head and neck: its prevention and treatment. Clin Plast Surg 2016;43:739-45.

8. Momeni A, Kim RY, Kattan A, Lee GK. Microsurgical head and neck reconstruction after oncologic ablation: a study analyzing health-related quality of life. Ann Plast Surg 2013;70: 462-9.

9. Sassler AM, Esclamado RM, Wolf GT. Surgery after organ preservation therapy: analysis of wound complications. Arch Otolaryngol Head Neck Surg 1995;121:162-5.

10. Anschutz L, Nisa L, Elicin O, Bojaxhiu B, Caversaccio M, Giger R. Pectoralis major myofascial interposition flap prevents postoperative pharyngocutaneous fistula in salvage total laryngectomy. Eur Arch Otorhinolaryngol 2016;273:3943-9.

11. Galli J, De Corso E, Volante M, Almadori G, Paludetti G. Post- laryngectomy pharyngocutaneous fistula: incidence, predisposing factors, and therapy. Otolaryngol Head Neck Surg 2005;133:689-94.

12. Magdy EA. Surgical closure of postlaryngectomy pharyngocutaneous fistula: a defect based approach. Eur Arch Otorhinolaryngol 2008;265:97-104.

13. Gupta B, Johnson NW, Kumar N. Global epidemiology of head and neck cancers: a continuing challenge. Oncology 2016;91: 13-23.

14. Vamadeva SV, Henry FP, Mace A, Clarke PM, Wood SH, Jallali N. Secondary free tissue transfer in head and neck reconstruction. J Plast Reconstr Aesthet Surg 2019;72:1129-34.

15. Dvorak Z, Pink R, Michl P, Heinz P, Tvrdy P. Pedicled pectoralis major flap in head and neck reconstruction: our experience. Acta Chir Plast 2019;60:26-9.

16. Delanian S, Lefaix JL. Current management for late normal tissue injury: radiation-induced fibrosis and necrosis. Semin Radiat Oncol 2007;17:99-107.

17. Martinez DC, Badhey A, Cervenka B, Zender C, Tang A, Patil Y. Surgical techniques for head and neck reconstruction in the vessel-depleted neck. Facial Plast Surg 2020;36:746-52.

18. Chia HL, Wong CH, Tan BK, Tan KC, Ong YS. An algorithm for recipient vessel selection in microsurgical head and neck reconstruction. J Reconstr Microsurg 2011;27:47-56.

19. Yazar S. Selection of recipient vessels in microsurgical free tissue reconstruction of head and neck defects. Microsurgery 2007;27:588-94.

20. Yano T, Okazaki M, Yamaguchi K, Akita K. Anatomy of the middle temporal vein: implications for skull-base and craniofacial reconstruction using free flaps. Plast Reconstr Surg 2014; 134:92e-101e.

21. Chung JH, Kim KJ, Jung KY, Baek SK, Park SH, Yoon ES. Recipient vessel selection for head and neck reconstruction: a 30 year experience in a single institution. Arch Craniofac Surg 2020;21:269-75.

22. Ibrahim AE, Adelman DM, Parham C, Hong Z, Villa M, Chahine FM, et al. The external jugular vein used as recipient vessel in head and neck free flap reconstruction: outcomes compared to the internal jugular vein. J Craniofac Surg 2019;30: 178-83.

23. Xu ZF, Duan WY, Zhang EJ, Bai S, Tian Y, Tan XX, et al. Transverse cervical vessels as recipient vessels in oral and maxillofacial microsurgical reconstruction after former operations with or without radiotherapy. World J Surg Oncol 2015;13:183.

24. Kim HS, Chung CH, Chang YJ. Free-flap reconstruction in recurrent head and neck cancer: a retrospective review of 124 cases. Arch Craniofac Surg 2020;21:27-34.

25. Aycock JK, Stenson KM, Gottlieb LJ. The thoracoacromial 
trunk: alternative recipient vessels in reoperative head and neck reconstructive microsurgery. Plast Reconstr Surg 2008; 121:88-94.

26. Kwon D, Genden EM, de Bree R, Rodrigo JP, Rinaldo A, Sanabria A, et al. Overcoming wound complications in head and neck salvage surgery. Auris Nasus Larynx 2018;45:113542.

27. Suh JM, Chung $\mathrm{CH}$, Chang YJ. Head and neck reconstruction using free flaps: a 30-year medical record review. Arch Craniofac Surg 2021;22:38-44. 